Тетермазова З.В.

\title{
Неизвестный гравированный портрет великого князя Павла Петровича из собрания ГМИИ им. А.С. Пушкина. Опыт интерпретации
}

Аннотация: В статье рассматривается уникальный оттиск портрета великого князя Павла Петровича, хранящийся в собрании ГМИИ им. А.С. Пушкина. Гравюра была исполнена и напечатана в технике офорта и резца немецким мастером И.Э. Нильсоном в Аугсбурге предположительно в последней трети XVIII века и имеет сложную аллегорическую программу. Однако, помимо сопровождающих образ текстов и аллегорических изображений, этот эстамп привлекает внимание тем, что по всей поверхности листа сделаны небольшие надрезы, которые образуют самостоятельный декоративный рисунок, изящно дополняющий изображение. Это отличает рассматриваемый портрет среди памятников подобного рода и вызывает особенный интерес. Обращаясь к стилистическому и иконологическому методам исследования, автор предпринимает попытку расшифровать программу изображения, определить обстоятельства и причинь создания надрезов, тем самым приблизившись к личности того, кто сподобился их произвести. Сделанные на листе надрезы тонко связаны с зашифрованным в изображении смыслом. Имя владельца гравюры, столь остроумно усовершенствовавшего композицию, пока остается загадкой. Однако, на основании сохранившихся свидетельств, автор статьи предпринимает попытку составить его «портрет», а также реконструировать культурный и политический контекст, в котором гравюра создавалась и существовала. Введение в научный оборот столь необычного памятника представляется особенно ценным и расширяет наше представление о культуре эпохи.

Ключевъе слова: Гравюра, портрет, XVIII век, немецкое искусство, русское искусство, масонство, Екатерина II, Павел I, Дмитрий Александрович Ровинский, офорт.

Review: The article is devoted to a unique print of a portrait depicting Paul I of Russia. The engraved portrait is stocked in the collection of the Pushkin State Museum of Fine Arts and was made and printed using the calligraphic etching and cutting method by a German craftsman I. Nilson in Augsburg supposedly in the last third of the XVIIIth century and has a complex allegoric program. However, besides associated texts and allegoric images, the engraving has one very interesting feature. Over the entire engraving, there are small cuts that make an individual decorate pattern elegantly completing the general image. This distinguishes the aforesaid portrait from other artwork of the kind and thus provokes special interest. Appealing to the stylistic and iconological research methods, the author makes an attempt to decode the image program, to define circumstances and reasons for making such cuts, and to get an insight about the personality of the one who created them. The cuts are associated with the meaning of the engraving encoded in the image. The name of the owner of the engraving who was so witty to improve the composition in this way is still a mystery. However, based on the evidence, the author of the article tries to create a 'portrait' of the owner as well as to describe the cultural and political environment in which the engraving was created. By introducing such a unique piece of art, the author of the article makes a valuable contribution and extends our image of the cultural life of that epoch.

Keywords: Engraving, portrait, XVIII th century, German art, Russian art, Freemasonry, Catherine the Great of Russia, Paul I of Russia, Dmitry Rovinsky, calligraphic etching.

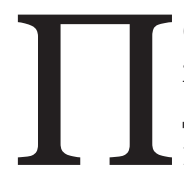
оводом для написания статьи послужил один необычный эстамп, увиденный автором в гравюрном кабинете ГМИИ им. А.С. Пушкина (инв. ГР-5465). Он представляет собой небольшое изображение великого князя Павла Петровича, исполненное в технике офорта, резца и пунктира и в настоящее время вклеенное в один из томов собрания русских гравированных портретов Д.А. Ровинского (1824-1895). Образ наследника дополнен нарядным изобразительным обрамлением, в котором небольшой овальный портрет смотрится как миниатюра, вставленная в изящную фарфо- 
ровую подставку. Сам принцип построения композиции, где изображения соединяются с текстом, воспроизводит структуру эмблемы [1, с. 7-29; 2, с. 347; 3; 4], что, наряду с обилием аллегорий и символов, было традиционно для риторической культуры XVIII столетия, особенно при создании портретных гравюр, предполагая прочтение скрытого в композиции аллегорического смысла.

Латинский текст в картуше над портретом - «Clara in Luce refulsit / Virg. L. 1» («Ярким светом сиял / Вирг. Кн. 1») - является цитатой из «Энеиды» Вергилия, отсылающей просвещенного зрителя к фрагменту поэмы, где говорится о том, как античный герой Эней, сын Анхиза и богини Венеры, явился перед народом в сиянии божественного света (I, 580-591):

Первым Энея Ахат ободряет:

«Отпрыск богини,

Дума какая, скажи, у тебя в душе зародилась?

Видишь, опасности нет, и спутники с флотом вернулись.

Только один не вернулся корабль:

мы видели сами,

Как он тонул. В остальном же сбылись предсказанья Венеры».

Чуть лишь промолвил он так, -

и тотчас же вкруг них разлитое

Облако разорвалось и растаяло в чистом эфире.

Встал пред народом Эней:

божественным светом сияли

Плечи его и лицо, ибо мать сама даровала

Сыну кудрей красоту и юности блеск

благородный,

Радости гордый огонь зажгла в глазах у героя [5, с. 157].

Павел, подобно Энею, был сыном божественной матери, ибо Екатерина II в то время многократно прославлялась как богиня - «Минерва», «Паллада», «Астрея» и пр. Интересно, что издание первого полного перевода «Энеиды» на русский язык, посвященное «Его Императорскому Высочеству Пресветлейшему Государю Великому Князю Цесаревичу Павлу Петровичу, Российскаго Престола Наследнику, Герцогу Голштейншлезвигскому, Сторманскому и Дитмарсенскому, Графу Олденбургскому и Делменгортскому и протчая Милостивейшему Государю» [6, с. [3]], предваряло следующее стихотворное обращение к Павлу, написанное переводчиком В.П. Петровым «Генваря 1 дня, 1770 года»:
Маронова ума во век прехвальный плод, Пречудный образец витийственных красот В стихи Российскаго переложенный слова Прими, Великий Князь, под ону тень покрова, Какую сам ему Октавий подавал,

Что света скиптр всего в деснице обращал;

Какую Мать твоя простерла на науки.

$<\ldots>$

Мне лик Ея доброт воображать приятно;

Приятно воображать о будущей судьбе

Готовящей открыть нам зрелый плод в Тебе:

Как рождышей в след паря звук Росских хвал умножишь!

Как гордых под пяту противников положишь! $<\ldots>$

Ты мысль мне озари и будь мой Аполлон $[6$, c. $[5-6]]$.

Упоминание божественной Матери (подразумевается, очевидно, Екатерина II), чей лик («лик Ея доброт») автору «приятно воображать» в образе «Великого Князя» (Павла Петровича), и уподобление его богу Аполлону - это явная отсылка к содержанию четвертой эклоги «Буколик» Вергилия, где сивилла предсказывает скорое наступление золотого века - царства Сатурна, когда с появлением Девы (Астреи) и рождением божественного младенца воцарится новое племя людей, и миром будет править покровитель искусств Аполлон:

Круг последний настал по вещанью пророчицы Кумской,

Сызнова ныне времен зачинается строй величавый,

Дева грядет к нам опять, грядет Сатурново царство.

Снова с высоких небес посылается новое племя.

К новорожденному будь благосклонна, с которым на смену

Роду железному род золотой по земле расселится.

Дева Луцина! Уже Аполлон твой над миром владыка [5, с. 45].

В эпоху Екатерины II миф о Деве Астрее, дочери Зевса и Фемиды, покинувшей землю вследствие зол и несправедливостей, достиг необыкновенного расцвета и интерпретировался, как правило, именно в соответствии с метафорикой четвертой эклоги «Буколик» [7, с. 57-104]. Императрица отождествлялась с Астреей, а малолетний наследник Павел Петрович, соответственно, играл роль божественного отрока, с рождением которого должен был наступить золотой век, царство мира, процветания и справедливости. 
Все это созвучно изображению на гравюре, где справа образ великого князя озаряет факелом крылатый Сатурн (или Кронос, бог Времени [8, с. 258-259] и отец Зевса, дочерью которого являлась Астрея), украшенный гирляндами из цветов, что вместе с изображениями двуглавого орла, глобуса, книг, пушек, пушечных ядер и знамен можно расшифровать как грядущее наступление царства Сатурна, основанного на просвещении (книги и глобус) и военной мощи (пушки, ядра и знамена). Учитывая известные исторические обстоятельства прихода к власти Екатерины II (имеется в виду дворцовый переворот 28 июня 1762 г., во время которого был свергнут император Петр III и на престол взошла его супруга Екатерина II), в ее правление метафизика Астреи предполагала конкретную политическую интерпретацию, связанную с идеей регентства императрицы при малолетнем Павле Петровиче и представлением о том, что ее миссия заключается, прежде всего, в «спасении» законного наследника, «божественного младенца» (Павла). Однако наследническая парадигма мифа об Астрее, популярная в первое время после переворота, когда для обоснования легитимности прихода власти Екатерина позиционировалась как «спасительница» будущего императора, впоследствии оказалась неприемлемой для торжествующей правительницы. В этом отношении программа портрета в большей степени близка мнению представителей оппозиционных кругов, связанных в частности с воспитателем наследника Н.И. Паниным и полагавших, что роль Екатерины исчерпается «спасением сына», на правление которого возлагались большие надежды.

Кроме того, при более близком рассмотрении гравюры обнаруживаются детали, которые выглядят в высшей степени необычно. Изображение отпечатано на тонком листе бумаги и очень аккуратно вырезано по контуру, следуя очертаниям каждой травинки и цветка, украшающим обрамление, а по всей поверхности листа сделаны небольшие надрезы. Последние не соответствуют ни контуру фигур, ни штрихам, что исключает возможность их прикладного назначения для создания копии. Между тем, перфорации исполнены необыкновенно умело и тонко и образуют самостоятельный декоративный рисунок, изящно дополняющий изображение, а легкая рыжевато-коричневая тонировка придает образу особенную глубину и воздушность. Надрезы и тонировка здесь столь уместны и гармоничны, что, кажется, могли быть исполнены самим автором эстампа.

Как свидетельствует латинская надпись, сохранившаяся на другом оттиске (инв. ГР5468), гравюра была создана и опубликована немецким художником И.Э. Нильсоном в Аугсбурге, согласно дарованной императором привилегии. Справа под изображением можно прочесть: «I: E: Nilson fec: et excud: A: V.» - «И.Е. Нильсон исполнил и напечатал. A.V.». «A.V.», очевидно, расшифровывается как «Augusta Vindelicorum»- латинское название города Аугсбурга. Слева внизу написано: «Cum Priv: S: C: R: Maj.», то есть «Cum Privilegio Sacrae Caesaris Majestatis» - согласно привилегии в пределах юрисдикции императоров Священной Римской империи [9, c. 134]. «Cum Privilegio» - «с разрешения и с защитой авторских прав» [10, с. 195]. Имеется в виду изображение, которое напечатано с разрешения императора, что было общепринятой практикой в юрисдикции Священной Римской империи германской нации в XVII-XVIII вв. По всей вероятности гравюра исполнялась приблизительно в 1770-х - 1780$\mathrm{x}$ годах по эстампу работы Д.Г. Герасимова (офорт, резец; 1762) [11, стб. 1423-1424, № 2], который восходит к живописному оригиналу кисти Ф.С. Рокотова (холст, масло; $1761 ;$ ГРМ) [12, c. 142, № 365].

Иоганн Эсайя Нильсон / Johannes Esaias Nilson (1721, Аугсбург-1788, Аугсбург) был немецким художником-миниатюристом, рисовальщиком, гравером и издателем, ярким представителем южно-немецкого рококо. Как истинный мастер этого стиля, особенное внимание он уделял декоративной красоте изображения. Большинство его работ строится на тонкой игре с различными уровнями изобразительной иллюзии, неуловимых переходах между уровнями репрезентации и значениями форм, когда одна и та же субстанция поочередно становится землей, водой, архитектурой и абстрактным орнаментальным обрамлением [13]. Эти качества сообщают его вещам особенное очарование. Однако, никаких свидетельств о том, что он из художественных соображений разрезал подобным образом свои гравюры, не известно [14].

Характер перфораций таков, что если, например, поместить эстамп на цветную подложку, она будет просвечивать сквозь вырезанные на нем отверстия, и лист обретет дополнительные декоративные качества. Мож- 
но было бы предположить, что тот, кто проделал столь кропотливую работу, намеревался наклеить его на какой-либо предмет мебели или шкатулку. Такое практиковалось с середины XVIII в. в Европе. «В середине XVIII в. стало модным вырезать гравюры, наклеивать их на лаковые подносы и другие предметы, раскрашивать и покрывать прозрачными лаками. Когда это хобби обрело большую популярность, стали публиковать и в виде отдельных листов, и в альбомах наборы гравюр для самодеятельности, сопровождавшиеся специальными инструкциями» [15, с. 40]. Одно из самых популярных изданий такого рода «Дамское развлечение» Р. Сэйера [16], которое предназначалось для любителей и неоднократно переиздавалось. Советы по раскрашиванию и покрытию лаком гравюр встречаются и в более раннем издании - в трактате Дж. Сталкера и Дж. Паркера 1688 г. [17]. Впоследствии это увлечение распространилось и в России. Сохранились, например, табакерки, исполненные на фабриках П.И. Коробова П.В. Лукутина и А. Эка (?) в первые десятилетия XIX в. из папье-маше с наклеенными на них гравированными портретами и покрытые лаком $[18$, с. 49 , № 19- 20, с. $68-69$, № 5556.]. На них, однако, отсутствуют надрезы, которые в данном случае придают листу особенную нарядность и декоративную красоту.

Скорее всего, для описанных выше манипуляций имелись иные, более тонко обоснованные причины. Возможно, предполагалось, чтобы гравюра пропускала свет, тем самым ясно воплощая зашифрованное в программе портрета уподобление Павла герою Энею, который «ярким светом сиял». Тема света особенно акцентирована еще и благодаря тому, что в руке у Сатурна, вопреки традиции, изображена не коса (« ... в руке у него коса, показывая чрез то, что он все пожинает» [8, с. 258-259]), а горящий факел. Очевидно, человек, сделавший на гравюре надрезы, пожелал подчеркнуть именно эту ее особенность, несомненно, питая большие надежды на будущее царствование Павла. С образом света связано и само имя наследника, святым покровителем которого был апостол Павел, или Савл, обратившийся в христианство после того, как на пути в Дамаск его внезапно осиял свет с неба и раздался голос: «Савл, Савл! Что ты гонишь Меня?».

Интересно представить себе этот эстамп помещенным, например, на экран лампы-омракля (омраклем во времена Екатерины II называли настольную лампу-подсвечник с полупрозрачным экраном, на котором помещали изображения, что создавало иллюзию ожившей картинки) или в Волшебшый фонарь (лат. - Laterna magica - аппарат для проекции изображений, распространенный в XVII - XX вв.), внутри которого в те годы ставили свечу или лампаду. В Прибавлениях к Санктпетербургским ведомостям неоднократно встречаются объявления об их продаже в России в $1770-\mathrm{x}-1790-\mathrm{x}$ гг. [19, с. $138 ; 20$, с. 1999-200о]. Это еще более усилило бы эффект сияния, ибо тогда, благодаря сделанным на листе отверстиям, изображение оказалось бы пронизано лучами яркого теплого света.

Имя владельца гравюры, столь остроумно и тонко усовершенствовавшего композицию, пока остается загадкой. Неизвестно и то, каким образом этот оттиск оказался в коллекции Д.А. Ровинского. Поскольку он не описан в его «Словаре русских гравированных портретов» [11, стб. 1424, № 4], можно считать, что лист был приобретен уже после публикации третьего тома словаря - то есть после 1888 года.

Несомненно, автор сих изящных дополнений был человеком прекрасно образованным, жил в Российской империи или был тесно с ней связан, обладал художественным талантом и тонким вкусом, умел и любил разгадывать скрытые в изображениях смыслы и к тому же с симпатией относился к Павлу Петровичу. Все это позволяет предположить в нем масона. Действительно, представители общества вольных каменщиков видели в молодом наследнике будущего справедливого и просвещенного правителя, способного принести мир и благоденствие империи. В напечатанном в 1784 году типографией И.В. Лопухина «Магазине свободно-каменьщическом...» помещена, в частности, такая масонская песня с обращением к Павлу:

Залог любви небесной

В Тебе мы ПАВЕЛ, зрим,

В Чете Твоей прелестной

Зрак Ангела все чтим.

Украшенный венцем,

Ты будешь нам Отцем!

$<\ldots>$

Уже Ты видишь ясно

Врата безсмертных в храм,

К которому опасно ступают по трудам!

Тебе, Минерва Мать,

Ты можешь путь скончать!

ПЕТРОВА кровь бесценна,

Богини Росской Сын, 
О Отрасль вожделенна,

Теки как исполин,

Блаженства вечный свет

Куда Тебя ведет! [21, с. 132-133]

По мнению историка С.П. Мельгунова, Павел I «более чем кто-либо из царей был связан невидимыми нитями с масонством» [22, с. 80]. Когда Павел был еще наследником престола, особенный интерес к нему проявляли берлинские начальники ордена розенкрейцеров, пытавшиеся, через тайные масонские каналы установить с ним связь [23, с. 149]. Значительную роль в этом процессе сыграл архитектор В.И. Баженов, который также был масоном и неоднократно встречался с великим князем [24]. Впоследствии масоны посвящали Павлу I оды, именовали его «солнцем наших дней», а павловское царствование - «возрождением» [25, с. 39].

В пользу причастности владельца гравюры масонству свидетельствует и тот факт, что в символике этого общества особенную роль играл образ света. В одной из песен с обращением к масонам говорилось:

Настал теперь тобою

Давно желанный час,

Трояким озарился

Ты светом между нас,

И став нам верный брат,

В восторге пой: виват, виват, виват!

Не пышность, не богатство,

Ты видишь в сих местах:

Едину добродетель ты слышишь во устах.

Здесь все ее твердят,

Глася всегда: виват, виват, виват!

Здесь вольность и равенство

Воздвигли вечный трон,

На них у нас основан

Полезный наш закон,

Он нам любим и свят;

Мы все гласим: виват, виват, виват!

Хотяб владетель света

Соделался Масон,

Он должен сам хранити

Полезный наш закон.

И быть нам верный Брат

Глася всегда: виват, виват, виват! [21, с. 138-139]
В масонских текстах неоднократно упоминаются «свет истинный» [26, с. 125], что «свет умножится чрез свет» [26, с. 127], «что Бог есть любовь и свет», «лучезарный троякий свет» [26, с. 129] и пр.

О Братья! вы себя

Познать в себе старайтесь,

И Орден возлюбя,

Млеком его питайтесь!

Вы Соломонов храм

Чрез три раза тремя создать ищите,

Гармоний вечной красотам

Олтарь в нем сотворите!

Дух света в облаках

Прозрачных и нетленных,

Тогда во красотах явится совершенных

[26, c. 137].

Вольные каменщики вели летоисчисление от того мига, когда Господь произнес: «Да будет Свет!», а масонский ритуал посвящения предполагал движение от тьмы к свету, когда кандидату завязывали глаза, а после того как он проходил испытания и выслушивал наставления снимали повязку. В таком случае, изображение Павла, на котором, благодаря отверстиям, «свет умножился чрез свет», могло быть связано и с его посвящением в масоны и могло служить, например, тайным масонским посланием, в котором сообщалось о причастности великого князя братству вольных каменщиков или выражалась надежда на его поддержку.

Все вышеизложенное в значительной степени остается на уровне догадок и предположений, веских фактических подтверждений которым автору настоящей статьи пока найти не удалось. Этот небольшой портретный эстамп все еще таит в себе интересные пути исследования, связанные не столько с вопросами художественного совершенства, сколько с проблемой бытования вещи, с культурным и политическим контекстом, в котором она создавалась и существовала, уводя заинтересованный взгляд в те сферы, где жизнь соединялась с красотой.

\section{Библиография:}

1. Алексеева М.А. Жанр конклюзий в русском искусстве конца XVII - начала XVIII в. // Русское искусство барокко: Материалы и исследования. М., 1977. - С. 7-29.

2. Тарасов О.Ю. Икона и благочестие. Очерки иконного дела в имп. России. М., 1995. - 495 с.

3. Махов А.Е. «Печать недвижных дум» // Эмблемы и символы / Вступ. ст. и коммент. А.Е. Махова. М., 2000. - C. 5-20. 
4. Карев А.А. К вопросу о модификациях портретного образа в русской живописи и графике XVIII века // Русское искусство Нового времени. Исследования и материалы: Сборник статей. - Вып. 8. М., 2004. - C. 5-20.

5. Публий Вергилий Марон. Буколики. Георгики. Энеида / пер. с лат. С. Шервинского, С. Ошерова. М., 2007. - 539 с.

6. Вергилий Марон, Публий. Еней / Героическая поема Публия Виргилия Марона. Переведена с Латинскаго Васильем Петровым. СПб., 1770. - 42 с.

7. Проскурина В. Мифы империи: Литература и власть в эпоху Екатерины II. М., 2006. - 322 с.

8. Иконологический лексикон, или Руководство к познанию живописнаго и резнаго художеств, медалей, эстампов и проч. с описанием, взятым из разных древних и новых стихотворцев / С французскаго переведен академии наук переводчиком Иваном Акимовым. СПб., 1763. -328 с.

9. Griffiths A. Prints and Printmaking: An Introduction to the History and Techniques. London, 1996. $-160 \mathrm{p}$.

10. The Grove Encyclopedia of Materials and Techniques in Art. Oxford, 2008. - 864 p.

11. Ровинский Д.А. Подробный словарь русских гравированных портретов. Т. 3. СПб., 1888. - 2208 стб.

12. Государственный Русский музей. Живопись XVIII в.: Каталог. Т. 1. СПб., 1998. - 205 с.

13. Howard Creel Collinson. Johann Esais Nilson. The Rise \& Fall of Augsburg Rococo // The Print Collector's Newsletter, Vol. 25, No. 3 (July-August 1994). - P. 89-92.

14. Gun-Dagmar Helke: Johann Esaias Nilson (1721-1788): Augsburger Miniaturmaler, Kupferstecher, Verleger und Kunstakademiedirektor. München, 2004. - 321 p.

15. English transfer-printed pottery and porcelain: a history of over-glaze printing / by Cyril Williams-Wood. London, 1981. $-249 \mathrm{p}$.

16. Sayer R. The Ladies Amusement: Or, Whole Art of Japanning Made Easy. London, 1762. -6 p.

17. Stalker, J., Parker, G. A treatise of japaning [sic] and varnishing : being a compleat discovery of those arts, with the best way of making all sorts of varnish ... : together with above an hundred distinct patterns for japan-work ... engraven on 24 large copper-plates. Oxford, 1688. $-148 \mathrm{p}$.

18. Государственный Эрмитаж. Русские художественные лаки XVIII - XX веков. Каталог коллекции. СПб., 2009. $-256 \mathrm{c}$.

19. Санктпетербургские ведомости, 1779, № 10. - С.131-142.

20. Санктпетербургские ведомости, 1793, № 83. - С.1989-2012.

21. Магазин свободно-каменьщической, содержащий в себе: Речи, говоренныя в собраниях; песни, письма, разговоры и другия разныя краткия писания, стихами и прозою; В 7 томах, а каждый том в 3 частях состоящий. Т. 1 Ч. 1. М., 1784. - 141 с.

22. Мельгунов С.П. Один из русских розенкрейцеров // Голос минувшего. М., 1917. № 1. - С. 73-83.

23. Брачев В.С. Масоны и власть в России (XVIII - первая четверть XIX вв.). Учебное пособие. СПб., 2000. $-226 \mathrm{c}$.

24. Янчук Н.А. Знаменитый зодчий В.А. Баженов и его отношение к масонству // Журнал министерства народного просвещения. Пг., 1916. № 12. - С. 167-238.

25. Сахаров В. «Калигулы последний час...» Император Павел I и вольные каменщики // Родина. М, 1997. № 7. - C. 38-41.

26. Магазин свободно-каменьщической, содержащий в себе: Речи, говоренныя в собраниях; песни, письма, разговоры и другия разныя краткия писания, стихами и прозою; В 7 томах, а каждый том в 3 частях состоящий. Т. 1 Ч. 2. М., 1784. - 144 с.

\section{References (transliterated):}

1. Alekseeva M.A. Zhanr konklyuzii v russkom iskusstve kontsa XVII - nachala XVIII v. // Russkoe iskusstvo barokko: Materialy i issledovaniya. M., 1977. - S. 7-29.

2. Tarasov O.Yu. Ikona i blagochestie. Ocherki ikonnogo dela v imp. Rossii. M., 1995. - 495 s.

3. Makhov A.E. «Pechat' nedvizhnykh dum» // Emblemy i simvoly / Vstup. st. i komment. A.E. Makhova. M., 2000. - S. 5-20.

4. Karev A.A. K voprosu o modifikatsiyakh portretnogo obraza v russkoi zhivopisi i grafike XVIII veka // Russkoe iskusstvo Novogo vremeni. Issledovaniya i materialy: Sbornik statei. - Vyp. 8. M., 2004. - S. 5-20.

5. Publii Vergilii Maron. Bukoliki. Georgiki. Eneida / per. s lat. S. Shervinskogo, S. Osherova. M., 2007. - 539 s.

6. Vergilii Maron, Publii. Enei / Geroicheskaya poema Publiya Virgiliya Marona. Perevedena s Latinskago Vasil'em Petrovym. SPb., 1770. - 42 s. 
7. Proskurina V. Mify imperii: Literatura i vlast' v epokhu Ekateriny II. M., 2006. - 322 s.

8. Ikonologicheskii leksikon, ili Rukovodstvo k poznaniyu zhivopisnago i reznago khudozhestv, medalei, estampov i proch. s opisaniem, vzyatym iz raznykh drevnikh i novykh stikhotvortsev / S frantsuzskago pereveden akademii nauk perevodchikom Ivanom Akimovym. SPb., 1763. - 328 s.

9. Griffiths A. Prints and Printmaking: An Introduction to the History and Techniques. London, 1996. - 160 p.

10. The Grove Encyclopedia of Materials and Techniques in Art. Oxford, 2008. - 864 p.

11. Rovinskii D.A. Podrobnyi slovar' russkikh gravirovannykh portretov. T. 3. SPb., 1888. - 2208 stb.

12. Gosudarstvennyi Russkii muzei. Zhivopis’ XVIII v.: Katalog. T. 1. SPb., 1998. - 205 s.

13. Howard Creel Collinson. Johann Esais Nilson. The Rise \& Fall of Augsburg Rococo // The Print Collector's Newsletter, Vol. 25, No. 3 (July-August 1994). - P. 89-92.

14. Gun-Dagmar Helke: Johann Esaias Nilson (1721-1788): Augsburger Miniaturmaler, Kupferstecher, Verleger und Kunstakademiedirektor. München, 2004. - 321 p.

15. English transfer-printed pottery and porcelain: a history of over-glaze printing / by Cyril Williams-Wood. London, 1981. - 249 p.

16. Sayer R. The Ladies Amusement: Or, Whole Art of Japanning Made Easy. London, 1762. -6 p.

17. Stalker, J., Parker, G. A treatise of japaning [sic] and varnishing : being a compleat discovery of those arts, with the best way of making all sorts of varnish ... : together with above an hundred distinct patterns for japan-work ... engraven on 24 large copper-plates. Oxford, 1688. - 148 p.

18. Gosudarstvennyi Ermitazh. Russkie khudozhestvennye laki XVIII - XX vekov. Katalog kollektsii. SPb., 2009. $-256 \mathrm{~s}$.

19. Sanktpeterburgskie vedomosti, 1779, № 10. - S.131-142.

20. Sanktpeterburgskie vedomosti, 1793, № 83. - S.1989-2012.

21. Magazin svobodno-kamen'shchicheskoi, soderzhashchii v sebe: Rechi, govorennyya v sobraniyakh; pesni, pis'ma, razgovory i drugiya raznyya kratkiya pisaniya, stikhami i prozoyu; V 7 tomakh, a kazhdyi tom v 3 chastyakh sostoyashchii. T. 1 Ch. 1. M., 1784. - $141 \mathrm{s.}$

22. Mel'gunov S.P. Odin iz russkikh rozenkreitserov // Golos minuvshego. M., 1917. № 1. - S. $73-83$.

23. Brachev V.S. Masony i vlast' v Rossii (XVIII - pervaya chetvert' XIX vv.). Uchebnoe posobie. SPb., $2000 .-226$ s.

24. Yanchuk N.A. Znamenityi zodchii V.A. Bazhenov i ego otnoshenie k masonstvu // Zhurnal ministerstva narodnogo prosveshcheniya. Pg., 1916. № 12. - S. 167-238.

25. Sakharov V. «Kaliguly poslednii chas...» Imperator Pavel I i vol’nye kamenshchiki // Rodina. M, 1997. № 7. - S. 38-41.

26. Magazin svobodno-kamen'shchicheskoi, soderzhashchii v sebe: Rechi, govorennyya v sobraniyakh; pesni, pis'ma, razgovory i drugiya raznyya kratkiya pisaniya, stikhami i prozoyu; V 7 tomakh, a kazhdyi tom v 3 chastyakh sostoyashchii. T. 1 Ch. 2. M., 1784. - 144 s. 